\title{
PARA ALÉM DO MAL-ESTAR NA ESCOLA: RESSIGNIFICANDO O ATO EDUCATIVO
}

Ademir Henrique Manfré

Universidade do Oeste Paulista - UNOESTE, Faculdade de Artes, Ciências, Letras e Educação - FACLEPP, Presidente Prudente,SP. E-mail: ademirmanfre@yahoo.com.br

\section{RESUMO}

O presente artigo se inscreve no amplo campo de pesquisa sobre formação de professores. Trata, portanto, da temática mal-estar docente, educação, formação e experiência educativa. Desse modo, o texto que ora apresentamos tem como propósito geral refletir sobre o mal-estar docente e a (im) possibilidade de sua ressignificação na escola. Objetiva apontar caminhos para o entendimento de que o mal-estar docente é um aspecto constitutivo da identidade do ser professor. Portanto, pode ser ressignificado a partir da experiência formativa, tese a qual defendemos amparados pelo referencial teórico da Escola de Frankfurt. Nossa preocupação foi pensar nos desafios postos pela atualidade para a realização de uma educação com base em uma experiência formativa.

Palavras-chave: Educação. Experiência (Erfahrung). Formação.

\section{BEYOND MALAISE IN SCHOOL: RE-SIGNIFYING THE EDUCATIONAL ACT}

\begin{abstract}
This article is part of a broad research field on teacher's formation. Here we discuss topics like teacher's malaise, education, formation, and educational experience. Then, our aim is to reflect about teacher's malaise and the (im) possibility of his/her re-signification in school. We indicate elements to understand that teacher's malaise is a kind of a constitutive aspect of teacher's identity in his/her own activity. Therefore, it can be re-signified from the formative experience; this is the thesis that we want to defend supported on theoretical framework of Frankfurt School. Our concern was to think about the challenges posed by nowadays to concretize an education with base on a formative experience.
\end{abstract}

Keywords: Education. Human development. Experience (Erfahrung). 


\section{INTRODUÇÃO}

O presente artigo se inscreve no amplo campo de pesquisa sobre formação de professores. Trata, portanto, da temática mal-estar docente, educação, formação e experiência educativa.

O "problema" do mal-estar docente continua sendo muito debatido em nossos dias, como podemos comprovar mediante a observação das diversas discussões que tratam dos sintomas contemporâneos e as preocupações dos indivíduos em relação ao seu próprio futuro.

Desse modo, o artigo que ora apresentamos tem como propósito geral refletir sobre o mal-estar docente e a (im) possibilidade de sua ressignificação na escola. Objetiva apontar caminhos para o entendimento de que o mal-estar docente é um aspecto constitutivo da identidade do ser professor. Portanto, não pode ser suprimido da prática docente por terapias de grupo, técnicas de relaxamento, entre outras, mas pode ser ressignificado, a partir da experiência formativa, tese a qual defendemos amparados pelo referencial teórico da Filosofia Crítica da Escola de Frankfurt.

Nossa preocupação foi pensar nos desafios postos pela atualidade para a realização de uma educação com base em uma experiência formativa. Por fim, partimos da consideração de que um dos elementos que possivelmente descreve o mal-estar docente é aquilo que foi descaracterizado, desconsiderado pela racionalidade instrumental, ou seja, a individualidade, o inconformismo, a formação (Bildung) a autonomia e o pensamento crítico.

\section{METODOLOGIA}

\section{CAMINHOS TRILHADOS PARA A ANÁLISE}

Este trabalho, de natureza teórica, situa-se no campo da Filosofia e da Filosofia da Educação e teve por objetivo investigar o que consiste o mal-estar docente que hoje se manifesta como "fenômeno" social no campo da educação.

Estivemos amparados em textos filosóficos de autores como Adorno e Walter Benjamin, os quais constituem o arcabouço teórico-interpretativo da análise proposta. A proposta dos frankfurtianos é pensar de que forma a razão transformou-se em irracionalidade voltada apenas para a dominação, discutindo aspectos inerentes à formação do indivíduo na qual a subjetividade é enfraquecida.

\section{DISCUSSÃO}

\section{MAL-ESTAR DOCENTE: UM DIAGNÓSTICO DA ATUALIDADE}

Reconhecido como um "fenômeno" internacional, a temática do mal-estar docente tem levado um número significativo de pesquisadores e educadores à produção de estudos investigativos em razão do elevado número de professores que vivenciam a angústia docente na prática do magistério. Nas pesquisas brasileiras, Esteve (1999) e Jesus (1998) são os pesquisadores mais citados, influenciando, sobremaneira, os estudos sobre essa temática.

Quando se remete ao mal-estar na escola, basicamente se está falando de um sentimento de angústia, frustração, descompasso, algo que não vai bem. Aparentemente é motivado por uma série de fatores de ordem pessoal e institucional que acometem os professores.

Quais aspectos que mais aparecem nessa discussão teórica? O que as pesquisas sobre o mal-estar docente sugere? Quais suas possíveis causas?

Abaixo, elencamos alguns pontos presentes nesse debate:

- indisciplina dos alunos;

- falta de investimentos na educação;

- falta de apoio dos pais na tarefa educativa;

- falta de apoio pedagógico;

- violência nas instituições escolares; 
- a extensa jornada de trabalho diário;

- baixos salários;

- o descompasso entre o discurso da escola e as novas exigências requeridas pelo mercado de trabalho.

E as consequências?

- depressões;

- síndromes;

- afastamentos;

- desistência da profissão docente;

- as mais variadas patologias.

Diante do exposto, não há como negar que a profissão docente é uma das mais estressantes.

Codo (2002), em parceria com a Confederação Nacional dos Trabalhadores em Educação (CNTE), apresenta uma pesquisa realizada com uma amostra de 30 mil trabalhadores em educação, tendo como resultado "a imagem do professor desanimado, queixoso até dos detalhes insignificantes sobre seu trabalho, sua clientela, tratando os alunos como se estivessem lidando com uma linha de montagem de salsichas..." (p. 237).

Nas pesquisas realizadas por Esteve (1999), as manifestações do mal-estar docente compreendem desde sintomas físicos como úlceras, insônias, tensão muscular, problemas de coluna, doenças cardiovasculares, afecções da laringe e pregas vocais a sintomas psicológicos, tais como ansiedade e depressão, até chegar a graves comprometimentos da saúde mental. Para o autor, o mal-estar sentido pelo professor é resultado das dificuldades no gerenciamento desse "fenômeno", ou ainda, da impossibilidade de sua superação.

Sabendo que o mal-estar docente é um tema bastante complexo, existem tentativas de mudar esse quadro, sendo necessárias algumas modificações para alcançar esse fim. É o que os autores chamam de situação de bem-estar docente. Aqui, de forma simplista, o mal-estar docente é visto como antônimo de bem-estar. E a escola deve favorecer situações geradoras de bem-estar como contraponto ao mal-estar vivenciado pelos professores. Atitudes positivas, resilientes, coping, situações de motivação, relaxamentos são os elementos identificados nas pesquisas ${ }^{1}$ brasileiras que traduzem formas de encarar, senão resolver o mal-estar docente vivenciado pelo professor na escola.

\section{RESULTADOS}

\section{OS LIMITES DO MAL-ESTAR DOCENTE}

Os estudos aqui apontados apresentam um limite. Nada é mencionado sobre a subjetividade, os desejos, a percepção dos professores. Apenas a insatisfação deles em sua ação cotidiana é levada em consideração na geração do mal-estar docente, desconsiderando outros elementos constitutivos do sofrimento do professor, como, por exemplo, o empobrecimento da experiência, ou melhor, a sua negação dentro da escola.

De maneira oposta aos estudos apresentados neste artigo, pensamos o mal-estar docente como elemento constitutivo do docente, como elemento formativo da experiência a qual estamos aqui reivindicando, permitindo novos sentidos, como construção, como lugar de ressignificação e de descontinuidade. Para tanto, utilizamos do referencial filosófico da Teoria Crítica da Escola de Frankfurt para sustentar nosso debate sobre os limites de se pensar o mal-estar docente na escola a partir do olhar das pesquisas aqui apontadas.

Mesmo não sendo um teórico da educação, Adorno, em suas reflexões filosóficas, oferece discussões fundamentais para pensarmos em uma educação autorreflexiva.

\footnotetext{
${ }^{1}$ Para citar algumas: Rodrigues (2011), Fonseca (2009), Prioste (2006), Leão (2003), Weber (2009), Sampaio (2008), Kobori (2010). 
O filósofo frankfurtiano apontará a autorreflexão como forma de cultivo do indivíduo. Nesse ponto, o filósofo supõe a ideia de indivíduo como elemento central para pensarmos a crítica. Somente um indivíduo capaz de se inconformar com a realidade ao seu redor pode ser portador da autorreflexão. Novamente surge a experiência ${ }^{2}$ como meio para se desenvolver a Bildung. Experiência possível de sensibilizar o indivíduo ante o outro, o diferente que se encontra tanto fora como em si mesmo.

Percebe-se que a concepção de resistência e de formação é o resultado depurado da exigência de Adorno (1996) de se manter a tensão do pensamento, a autorreflexão.

\section{CONCLUSÃO}

\section{RESSIGNIFICANDO O MAL-ESTAR DOCENTE}

Diferentemente dos autores que pensam o mal-estar docente enquanto algo a ser superado, solucionado, administrado no contexto pedagógico, pensamos tal problemática por meio da crítica, da autorreflexão enquanto elemento de tensão a respeito das condições objetivas e subjetivas que engendram a (des) construção da experiência no ambiente pedagógico. Pensar nos dias atuais na relação entre semiformação e pobreza da experiência implica em criar possibilidades de resistência do indivíduo perante a sociedade que o nega e o aniquila mediante o pensamento autorreflexivo.

Assim, ao relacionarmos o mal-estar docente com a pobreza da experiência, estamos dizendo que a impossibilidade da experiência acaba por traduzir-se também na ausência do pensamento autorreflexivo, pois tampouco a memória, o pensar o próprio pensamento, a narração são conservados nesse processo de danificação da subjetividade.

Nesse sentido, propomos ressignificar o mal-estar docente pela via da crítica, através da autorreflexão, rejeitando uma rasa interpretação que propõe a "resolução do mal-estar docente" (ou até mesmo a sua eliminação) pela via do bem-estar, de medidas preventivas, das estratégias de coping, da resiliência, das terapias comportamentais, do gerenciamento do mal-estar como propõem os teóricos do mal-estar docente.

A análise do mal-estar docente como constituinte do Magistério leva-nos a compreender que o ato de formar, da educação do outro, da formação do outro, implica em olhar para si mesmo, daquele que experiência o ato educativo.

Adorno (1996) adverte sobre a tendência contemporânea em que há o predomínio das vivências ao invés de experiência. No lugar da experiência, o que se passa é uma experiência substitutiva que, como o próprio nome sugere, substitui precariamente aquela experiência "[...] por um estado informativo pontual, desconectado, intercambiável e efêmero e que se sabe que ficará borrado no próximo instante por outras informações" (ADORNO, 1996, p. 405).

Diante da amplitude que caracteriza a temática, Adorno (1996) se empenha em denunciar a deficiência da formação dos indivíduos na contemporaneidade.

Adorno (1996) constata que a atual consciência não é apta à experiência. Por não possuir aptidão à experiência, essa consciência é caracterizada como coisificada. O filósofo vai dizer que a consciência coisificada é uma consciência amputada, pois é destituída do pensamento e da reflexão.

Em Adorno (1996), experiência implica em encontrar o eu no não-eu e o não-eu no outro. A experiência também passa por aquilo que Adorno (1996) chama de elaboração do passado, afirmando que a experiência pressupõe uma relação com o historicamente produzido. Não se trata de restaurar o passado, mas de nele buscar aquilo que foi perdido.

\footnotetext{
${ }^{2}$ Experiência, em Adorno (1996) identifica-se com formação (Bildung), resistência, autonomia, inconformismo, elementos esses negados pelo desenvolvimento da tecnologia, da mercantilização da cultura e da miséria da vida humana, levando os indivíduos a usurparem da experiência (Erfahrung) em favor da vivência (Erlebnis), a formação pela semiformação, o passado pela instantaneidade dos fatos corriqueiros.
} 
Propomos pensar o mal-estar na escola enquanto expressão de algo que está devindo, ou seja, o mal-estar como anúncio de desacomodação, que relativiza suas certezas e que faz com que o professor busque novos recursos e meios para lidar com os acontecimentos cotidianos.

O mal-estar é inevitável. Desse modo, propomos encará-lo como crítica, pautando-se pela possibilidade de recontar, experienciar. Assumimos o mal-estar docente enquanto trabalho de resistência, de inconformação, entendemo-lo como traço do ser professor, como um elemento que está no entrecruzamento do desejo de ensinar, educar, exercer a docência e as condições objetivas e subjetivas encontradas e mobilizadas nesse exercício, tendo a experiência como elemento-chave desse processo.

Assim, acreditamos ser possível e necessário analisar essa realidade do mal-estar docente de modo ampliado, com o objetivo de evitar o risco do reducionismo e de análises parciais.

Transformar a pobreza da experiência em experiência seria produzir uma nova experiência, mesmo a partir dessa própria experiência, como inconformismo e resistência.

\section{REFERÊNCIAS}

ADORNO, Theodor W. \& HORKHEIMER, Max. Dialética do esclarecimento: fragmentos filosóficos. Tradução de Guido Antônio de Almeida. Rio de Janeiro: Zahar ed., 1985.

. Teoria da semicultura. Tradução de Newton Ramos-de-Oliveira; Bruno Pucci; Claudia B. M. Abreu. Educação e sociedade, n 56, Campinas, São Paulo: Papirus, dezembro/1996, p. 388-411.

O que significa elaborar o passado. In: Theodor Adorno: educação e emancipação. Tradução de Wolfgang Leo Maar. Rio de Janeiro: Paz e Terra, 1995a, p. 29-50.

. Educação após Auschwitz. In: Theodor Adorno: educação e emancipação. Tradução de Wolfgang Leo Maar. Rio de Janeiro: Paz e Terra, 1995a, p. 119-138.

- Tabus acerca do magistério. In: Theodor Adorno: educação e emancipação. Tradução de Wolfgang Leo Maar. Rio de Janeiro: Paz e Terra, 1995b, p. 97- 118.

BENJAMIN, Walter. Experiência e pobreza. In: Obras escolhidas I. Tradução de Sérgio Paulo Rouanet. São Paulo: Brasiliense, 1994a.

. O narrador: considerações sobre a obra de Nikolai Leskov. In: Obras escolhidas I. Tradução de Sergio Paulo Rouanet. São Paulo: Brasiliense, 1994b.

. Sobre alguns temas em Baudelaire. In: BENJAMIN, W. Charles Baudelaire: um lírico no auge do capitalismo. Tradução José Martins Barbosa, Hemerson Baptista. São Paulo: Brasiliense, 1989 (obras escolhidas v. 3).

CODO, Wanderley (ORG.). Educação: carinho e trabalho. Burnout, a síndrome da desistência do educador, que pode levar à falência da educação. Petrópolis, Rio de Janeiro, Vozes/Brasília. Confederação Nacional dos trabalhadores em educação. Universidade de Brasília, Laboratório de Psicologia do trabalho, 2002.

ESTEVE, José. M. O mal-estar docente: a sala de aula e a saúde dos professores. São Paulo: EDUSC, 1999. 
FONSECA, Ana C. E. A. Contribuições da psicanálise a uma leitura do mal-estar docente na rede municipal de ensino em Olinda. 2009, 140 f. Dissertação (Mestrado em educação). Universidade Federal de Pernambuco, Recife/PE.

JESUS, Saul N. Bem-estar dos professores: estratégias para realização e desenvolvimento profissional. Porto: ed. Porto Ltda., 1998.

KOBORI, Carolina. Organização e condições de trabalho de professoras - mal-estar docente e permanência no emprego: estratégia defensiva? 2010,120 f. Dissertação (Mestrado em educação). Universidade Estadual de Campinas. Campinas.

LEAO, Cleri B. M. Entre o bem e o mal-estar docente: um retrato de professores do ensino superior privado. 2003,102 f. Dissertação (mestrado em educação).

PRIOSTE, Cláudia D. Diversidade e adversidade na escola: queixas e conflitos de professores frente à educação inclusiva. 2006, 163 f. Dissertação (Mestrado em educação). Universidade de São Paulo, São Paulo.

RODRIGUES, Lenira S. Do mal-estar ao bem-estar docente: uma análise de caso Argentina e Brasil. 2011, 111 f. Dissertação (Mestrado em educação). Pontifícia Universidade Católica do Rio Grande do Sul - PUC-RS. Porto Alegre/RS.

SAMPAIO, Adelar A. Programa de apoio ao bem-estar docente: construção profissional e cuidar de si. 2008,110 f. Dissertação (Mestrado em educação). Pontifícia Universidade Católica do Rio Grande do Sul. PUCRS, Porto Alegre.

WEBER, Sueli W. Uma investigação acerca dos fatores que contribuem para o mal-estar e o bemestar dos professores que trabalham com EAD. 2009,170 f. Tese (Doutorado em educação). Pontifícia Universidade Católica do Rio Grande do Sul, PUCRS, Porto Alegre. 